\title{
Estação Ferroviária de Pelotas: espaço de sociabilidade, visualidade e memória urbana*
}

\section{Railway Station of Pelotas: space of sociability, visuality and urban memory}

\author{
Maira Eveline Schmitz \\ Mestranda em História pela Universidade Federal de Pelotas \\ maira.schmitz@gmail.com
}

\section{Resumo:}

O tema deste artigo é o espaço ferroviário da cidade de Pelotas, no sul do Rio Grande do Sul, ao final do século XIX. Este foi um momento de mudança na materialidade urbana e busca-se, assim, inferir as novas sociabilidades e práticas sociais construídas no espaço ferroviário, bem como compreender as interpretaçóes e sentidos dados ao local. Para tanto, as fontes analisadas serão fotografias e jornais, utilizando-se as metodologias apropriadas. Indo além, pretende-se perceber como os sentidos dados ao espaço ferroviário naquele momento dialogam com sua situação material e patrimonial hoje.

Palavras-chave: Ferrovia; Pelotas;

História urbana

\section{Abstract:}

The present research work has a theme the railway area city of Pelotas, in southern of Rio Grande do Sul, at the end of the nineteenth century. This was a turning point in the urban materiality and seeks to thus infer the new sociability and social practices built into railway area as well as understand the interpretations and meanings given to the site. For this purpose, the sources will be analyzed photographs and newspapers, using appropriate methodologies. Going forward, we intend to understand how the meanings given to the railway area at that time dialogue with their material and patrimonial situation today.

Keywords: Railway; Pelotas;

Urban history 
elotas, sul do Estado do Rio Grande do Sul, está situada às margens do arroio Pelotas e do canal São Gonçalo. Ao fim da década de 1880, juntamente com Rio Grande e a capital Porto Alegre, era uma das cidades fortemente urbanizadas da Província de São Pedro, com o traçado urbano planejado, alta demografia para o período, casaróes imponentes e diversas praças e locais de lazer.

O historiador pelotense Mário Osório Magalhães chega mesmo a considerar o ano de 1890 como simbólico do fim de um período de expansáo e auge sócio-cultural - iniciado em 1860 -, o qual só teria sido possível em virtude das boas condiçôes urbanas e econômicas propiciadas pela produção charqueadora (MAGALHÃES, 1993: 11). O autor em seu trabalho dá ênfase às novas sociabilidades surgidas com o desenvolvimento de oportunidades e eventos culturais, artísticos e educacionais.

Observando-se as transformações morfológicas da cidade, uma intervenção urbana específica do fim deste período chama a atenção: a Estação da via férrea. Pelotas se situa no caminho da estrada de ferro do Rio Grande a Bagé, inaugurada, junto com as estaçóes, ao final do ano de 1884. Essa estrada seguia, em seu sentido geral, em paralelo à fronteira com o Uruguai, cortando uma região que, na época, era uma das mais rentáveis do Estado, com economia centrada na pecuária. As cidades de Rio Grande, Pelotas e Bagé, interligadas a partir da inauguração, representavam, assim, o tripé econômico gado-charque-porto (IPHAE, 2002: 21).

A cidade de Pelotas, neste momento, era o centro da economia do sul do estado, com a produçáo baseada nas charqueadas. O espaço urbano, como já mencionado, via aflorar um grande desenvolvimento, sendo a estação ferroviária, ao mesmo tempo, propiciadora desta expansão, impulsionando a cidade em direção ao porto e à mancha ferroviária, e limitadora, constituindo-se em uma barreira física para o crescimento citadino (IPHAE, 2002: 61).

A construção da linha e da estação, dessa forma, trouxe implicaçôes para o desenho urbano e para a organização morfológica da cidade. Acredita-se, contudo, que além da implicação material a entrada deste novo local de encontro no espaço urbano trouxe mudanças também no ritmo e no tempo citadinos, com a criação de um lugar de sociabilidades e de novas práticas sociais específicas. É sobre a construção deste novo espaço urbano e das relaçôes que nele ocorreram que pretende discorrer este trabalho.

A primeira parte do texto, assim, centra sobre as percepçôes e sentidos dados à construção e inauguração deste espaço, sobre a intervenção na morfologia e nas práticas sociais urbanas. Para tanto, serão utilizados como fonte os artigos veiculados pelos jornais pelotenses $A$ Nação, A Discussão e Onze de Junho do fim de 1884 e dos primeiros meses de 1885. Após, buscar-se-á compreender de que forma o espaço ferroviário foi constituindo-se em paisagem, imagem dotada de uma visualidade própria, através da análise de duas fotografias dos primeiros anos de funcionamento da Estação. Por fim, quer-se lançar o olhar sob uma perspectiva mais abrangente, procurando perceber como os sentidos dados ao espaço ferroviário naquele momento dialogam com sua situação material e patrimonial hoje.

\section{O ESPAÇO URBANO DA FERROVIA: SENSIBILIDADES E PRÁTICAS SOCIAIS}

A história das estradas de ferro no Rio Grande do Sul, de acordo com o inventário das estaçóes ferroviárias elaborado pelo Instituto do Patrimônio Histórico e Artístico do Estado, tem início em 1866, com os debates na Assembléia 
Provincial acerca da construção de uma linha que interligasse a zona de colonização alemã, no vale do Rio dos Sinos, com a capital Porto Alegre (IPHAE, 2002: 19). Posteriormente a esta linha pioneira foi sendo implantada na Província uma rede de estradas de ferro, seguindo quatro linhas principais: as Estradas de Ferro Porto Alegre - Uruguaiana, Rio Grande - Bagé, Santa Maria - Marcelino Ramos e Barra do Quarai - Itaqui.

A Estrada de Ferro Rio Grande - Bagé fazia parte de um projeto inicial apresentado, em 1872, pelo engenheiro J. Ewbank da Câmara, sendo denominada por ele de "Tronco Sul". Sua construção foi autorizada a partir de um decreto imperial, em 1873, juntamente com a linha Porto Alegre - Uruguaiana. A concessão de sua construção passou por vários nomes, sendo por fim concretizada a partir da fusão de duas empresas, a "Compagnie Imperiale des Chemins de Fer du Rio Grande do Sul” e a "Southern Brazilian Rio Grande do Sul Railway Company Limited” (IPHAE, 2002: 20).

No dia 02 de dezembro de 1884, em meio à efervescência das eleições provinciais - ocorridas ao primeiro dia do mês - inaugura-se esta estrada de ferro e, com ela, abrem-se oficialmente as estaçôes férreas da região ao uso público. Momento este que foi o ápice, ou o mais novo início, de um processo que animava havia décadas os debates políticos e o imaginário das populaçôes. Se já os projetos de linhas causaram discussões, com os preparativos da inauguração não foi diferente.

O jornal Onze de Junho, de 27 de novembro de 1884, traz um artigo sobre a reunião realizada pela comissáo organizadora dos festejos, nomeada pela câmara municipal. Nesta, a comissão se mostra contrariada pelo fato de que a cidade de Pelotas não teria recebido a "consideração" devida em relação à sua "importância e desenvolvimento"[1], deixando a Companhia de lhe delegar um lugar de relevância, considerando-a somente mais uma parada na viagem inaugural. Alegando que Pelotas foi posta à margem das cidades que marcavam o termo da estrada - Rio Grande e Bagé - a comissão opta, assim, por não realizar os festejos.

A mesma edição contém outra notícia, sobre um telegrama enviado pelo engenheiro responsável pela linha, Dr. Augusto Duprat, pedindo que os organizadores pelotenses mudassem sua posição. Foi respondido, de acordo com o jornal, com um pedido de revisão do plano da inauguração, condição indispensável para a realização dos festejos. O texto encerra com a seguinte frase: "Náo queremos favores, queremos tão somente a justiça e mais consideração" [2], o que indica uma posição do jornal favorável à determinação da comissão em garantir um relevo maior à cidade de Pelotas.

Se o Onze de Junho se coloca ao lado da comissão, o jornal A Discussão contesta a decisão tomada. No número de 29 de novembro de 1884, provavelmente em resposta à negociação ocorrida, afirma que "o capricho de poucos e a teimosia de outros, que entendem bem representar esta cidade, não poderam ser vencidas apezar das mais claras e convincentes explicaçôes, provas de attenção e pedidos constantes e leaes"[3]. Percebe-se a relutância em aceitar a decisão de poucos nomes como representante da vontade de toda a populaçáo pelotense. Por outro lado, pode-se inferir uma inclinaçáo deste jornal para com alguns membros da comissão que votaram a favor dos festejos, como os Srs. Álvaro Chaves, Nunes Vieira e Julio Martins Correa.

Ao fim das discussóes, a inauguração da estrada de ferro em 02 de dezembro, como indica a maioria das fontes, no trecho de Pelotas se deu sem grande
1 - Reunião. Onze de Junho, Pelotas, 27 nov. 1884. no 1552, Notícias, p.1.

2 - Ainda sobre a inauguração da estrada de ferro. Onze de Junho, Pelotas, 27 nov. 1884. no 1552, Notícias, p.2.

3 - Não há festejos. A Discussão, Pelotas, 29 nov. 1884. no 284, Correio do Dia, p. 2. 
4 - Festejos da inauguração da estrada de ferro, Onze de Junho, Pelotas, 06 dez. 1884. no 1559, Onze de Junho, p.1.

5 - Estrada de Ferro. A Discussão, Pelotas, 03 dez. 1884. no286, Correio do Dia, p. 2.

6 - Estrada de ferro. A Nação, Pelotas, 03 dez. 1884. Noticiário, p.2.

7 - Inauguração. Onze de Junho, Pelotas, $07 \mathrm{dez}$. 1884. no 1560, Notícias, p.1.

8 - Estrada de ferro. A Nação, Pelotas, 03 dez. 1884. Noticiário, p.2.

9 - Camara Municipal. A Discussão, Pelotas, 21 abr. 1884. no88, Correio do Dia, p. 2. entusiasmo. O Onze de Junho, no dia 06 de dezembro, considerou o momento um "desanimo", o qual não esteve à altura do melhoramento que significava para o sul e que muito desta situação foi ocasionada pela própria companhia da estrada ferro[4]. Além de não embandeirar os vagóes, a companhia deixou de expor a flâmula brasileira nas estaçóes, substituindo-a pela francesa. De forma simbólica, tem-se a representaçáo de quem realmente detinha o controle e, provavelmente, usufruiria da maior parte dos lucros: a empresa destinada a construção e gestão da estrada. O discurso de progresso da nação, sempre tão presente, vê-se ameaçado pelo descaso da própria responsável por fazê-lo acontecer.

A Discussão, do dia 03 de dezembro, definiu a comemoração como "fria e contristadora", afirmando que somente teria ido um "regular concurso de povo, que para lá se dirigia atrahido tão somente pela curiosidade", acusando de responsáveis por isto as "discórdias bairristas"[5]. O número d'A Nação, do mesmo dia, classificou a estação como muito concorrida, tendo um movimento de mais de 800 pessoas[6]. Várias posiçóes, assim, conforme os interesses dos jornais e suas percepçóes sobre o evento.

Independente do resultado dos festejos da inauguração, contudo, a intervenção que o funcionamento da Estação Férrea ocasiona na cidade já se fazia sentir. Um exemplo é a construção da linha de bondes, inaugurada a 07 de dezembro, conforme notícia do jornal Onze de Junho deste dia, justamente para fazer a ligação entre o centro da cidade, a partir da estaçáo central da Companhia Ferro Carril, e a estação da estrada de ferro, localizada mais perifericamente[7]. O jornal A Nação, de 03 de março de 1885 também atesta esta ligação, ao publicar os novos horários da linha de bonds, os quais se adequavam aos dos trens[8].

Outra intervenção urbana necessária, em virtude da existência da estrada de ferro, é a construção de uma nova avenida na cidade, que se dirigisse do centro para a estação. Esta foi discutida e aprovada pela câmara municipal, sendo declarado concluído o contrato pelo requerimento dos Srs. J. J. Dias Ferreira e J. Machado, conforme o número de 21 de abril de 1885 do $A$ Discussáo.[9] Nesta mesma reunião, deu-se à avenida o nome de Bernardo Souza - atual Dom Pedro II.

O espaço ferroviário, assim, não pode ser entendido somente como a estação, ou os trens e trilhos, mas como todo o complexo que acompanha as estruturas características - ruas, avenidas, praças, calçadas, comércio, hotéis, moradias. Esta compreensão, contudo, pode ir muito além da morfologia física: a ferrovia constitui-se em toda uma conjuntura que acompanha - e se faz acompanhar - do desenvolvimento urbano, mas também da transformação das relações de trabalho, da criação de novos hábitos, ritmos, paisagens e da própria constituição de sociabilidades.

Falar em sociabilidades requer indispensavelmente uma passagem pelo primeiro autor a discutir o conceito, Georg Simmel. De acordo com Heitor Frúgoli Jr., em suma, a sociabilidade de Simmel seria "a modalidade de interação entre indivíduos: o processo geral e os processos particulares de associação” (2007:9). $\mathrm{O}$ autor ressalta, contudo, que com as várias apropriaçóes do termo, este acaba podendo definir "tudo" e, assim, não explicar nada. Aponta, então, alguns direcionamentos possíveis de seu uso, entre os quais se opta, aqui, pela definição das "formas de sociabilidade enquanto possibilidades de construção temporária do próprio social entre estranhos ou atores sociais de condiçóes diversas, em que a interação em si constituiria o principal intuito" (FRÚGOLI JR., 2007: 23-4). Um dos maiores desafios, considera o autor, é identificar os lugares, em termos 
espaciais, que permitam a visibilidade destes vários tipos de interação social, cabendo "atentar aos espaços urbanos para onde costumam afluir diferentes grupos” (2007: 24). Acredita-se, assim, que o espaço ferroviário é um destes espaços.

Neste sentido, no caso de Pelotas pode-se observar não só mudanças na materialidade urbana, mas o surgimento de novas práticas sociais e de outros tempos da cidade; principalmente, o tempo de espera e o tempo de partida. A estação e a estrada de ferro tornam-se motivo e oportunidade para o encontro, para recepção e despedida - não que estas práticas já não existissem, como no cais do porto, mas adquirem novos significados por causa do espaço. Temos, então, casos mais isolados, como o das famílias que vêm passar o dia na cidade, recebendo as despedidas dos citadinos no momento do regresso - noticiado n' $A$ Nação, de 9 de dezembro de 1884 [10] -, ou até mesmo de pelotenses ilustres, como o candidato a deputado Dr. Francisco da Silva Tavares, o qual foi recebido na estação por "correligionários e amigos" com banda de música e "girândolas de foguetes" - conforme $A$ Nação de 12 de janeiro de 1885 [11].

Outros casos, por sua vez, chegaram a mobilizar toda a cidade - na opiniáo dos periódicos. O primeiro deles pode ser localizado já há uma semana após a inauguração oficial da linha. No dia 7 de dezembro ocorreram os festejos dos comerciantes de Pelotas conjuntamente aos da cidade de Bagé, os quais fazem, então, sua "verdadeira" comemoração em virtude do início do tráfego - independente do planejamento da Companhia e da presença da cidade do Rio Grande nas festas.

Nesta ocasião, a estação é palco para a espera, novamente com foguetes e bandas de música - Santa Cecília, Apollo e União, enumera o Onze de Junho de 10 de dezembro [12]. Neste mesmo número, o jornal afirma que "na gare da estação achavam-se para mais de 5 mil pessoas, representando todas as classes sociaes" [13]. Para $A$ Nação, publicada no mesmo dia, naquele espaço e nas imediaçóes "agglomeravam-se para mais de seis mil pessoas que para alli começaram a affluir desde as 3 horas da tarde", sendo que "a cidade parecia deserta, e o commercio, a pedido da sua respectiva commissáo, fechara os seus estabelecimentos"[14]. Tomando-se a informação de Magalhães (1993: 108), Pelotas contava em 1890 com 41.591 moradores no perímetro urbano; provavelmente a cidade não pareceria deserta, mas a média de 5 ou 6 mil pessoas movimentando o espaço ferroviário pode ser considerado expressivo, ainda que somente como simbólico de uma ideia a ser passada pelos periódicos.

Nesta mesma direção, tem-se ainda a passagem e estadia da Princesa Isabel e do Conde d'Eu em Pelotas, em fevereiro de 1885. Há notícias, principalmente no $A$ Discussão, do préstito que a segue até a estação para se despedir, quando de sua ida à cidade de Bagé e também da recepção quando de sua volta, onde, conforme o número de 23 de fevereiro de 1885, "desde ás 2 horas da tarde começou a affluir a estação da via férrea, vistosamente embandeirada, grande concurso de povo, em carros, em bonde e a pé"[15]. O interessante do caso da Princesa Isabel é que o município e o jornal incentivam à ida ao espaço da estação da via férrea, como no convite publicado no dia 20 de fevereiro, destinado "a todos os habitantes" para que fossem assistir à recepção - esta sempre caracterizada pelas bandas e pelos foguetes [16].

A partir destes exemplos, percebe-se que com o funcionamento da estrada de ferro são forjadas novas práticas sociais determinadas, localizadas no espaço específico que é o ferroviário. A chegada e a partida do trem regulam novos
10 - Festejos. A Nação, Pelotas, 09 dez. 1884. Noticiário, p.2.

11 - Dr. Francisco da Silva Tavares. A Nação, Pelotas.

12 - Manifestação. Onze de Junho, Pelotas, $10 \mathrm{dez}$. 1884. no 1561, Notícias, p. 2.

13 - Manifestação. Onze de Junho, Pelotas, $10 \mathrm{dez}$. 1884. no 1561, Notícias, p. 2.

14 - Festejos em Bagé. A Nação, Pelotas, 10 dez. 1884. Noticiário, p.1-2.

15 - S.S. A.A. imperiaes. A Discussão, Pelotas, 23 fev. 1884. no42, Correio do Dia, p.1.

16 - Princeza imperial. A Discussão, Pelotas, $20 \mathrm{fev}$. 1884. n40, Correio do

Dia, p.1. 


\section{Artigos \& Ensaios}

17 - Observatório de Greenwich. A Nação, Pelotas, 12 jan. 1884. no229, Noticiário, p.2.

18 - Manifestação. Onze de Junho, Pelotas, $10 \mathrm{dez}$ 1884. no 1561, Notícias, p.2.

19 - Cousas da estrada de ferro. Onze de Junho, Pelotas, 20 dez. 1884. no 1570, Notícias, p.2. tempos da cidade, seja nos horários do trânsito dos bondes, ou no tempo certo de afluir para a estação para partir ou chegar, ou ainda receber e se despedir dos passageiros. A descrição dos eventos que envolvem as viagens ferroviárias, pelos periódicos, geralmente apresenta o horário de partida e o de chegada, como que para deixar claras a duraçáo do passeio e a forma como o trem domina o espaço e o tempo. A relação locomotiva-relógio é sempre posta. Um exemplo inconteste é quando, conforme $A$ Naçáo de 12 de janeiro de 1885 , o observatório de Greenwich muda a forma de contar o tempo - passando o dia a ser marcado da meia-noite até 24 horas - e a expectativa é de que o novo sistema seja bem aceito, principalmente em virtude das estradas de ferro...[17]

Olhar o espaço ferroviário e as implicaçóes sociais que sua existência acarreta, no entanto, não consiste somente em ver mudanças de caráter "positivo", como o encontro, a festa, o domínio do cronológico-espacial, o desenvolvimento material urbano. A presença dos trilhos, da estação e da locomotiva traz novas rotinas e práticas que nem sempre são acolhidas sem conflitos ou tensóes. As dificuldades com a empresa estrangeira, o preço dos fretes e a falta de uma tabela fixa que os regule, as cargas não transportadas sem justificativa, são reclamaçóes recorrentes.

Outro fator de conflito observado pode ser visto à luz do que Henri Lefebvre (2001) considera um dos principais fatores da própria produção da cidade, produção da obra urbana: os conflitos entre os grupos sociais que habitam e pertencem ao urbano. A inauguração da estrada de ferro e da estação implica na inserção de um novo grupo social na cidade, o dos trabalhadores ferroviários. Em relação a estes, na visão dos periódicos analisados, as queixas são intermináveis, indo desde uma greve realizada em meio à viagem inaugural, passando pela falta de educação e grosserias frequentes dos usuários, chegando até a perda de bagagens.

É interessante a imagem do pessoal da estrada de ferro, construída principalmente pelo Onze de Junho, como trabalhadores que se portam como senhores do espaço férreo. No dia 10 de dezembro de 1884 afirma que estes se portaram com indignidade, "chegando alguns a prohibirem a entrada de famílias na gare" [18]; no dia 20 do mesmo mês há a denúncia que o transporte de bagagens e mercadorias se dá conforme o "capricho dos Srs. empregados", sendo que as pessoas que "têm a felicidade de valer alguma cousa para o pessoal da estrada de ferro, são immediatamente attendidas, como se o serviço se achasse perfeitamente organisado" e, por outro lado, "as que não têm essa felicidade, são, algumas vezes, tratadas bruscamente e desattendidas em suas justas pretençóes"[19].

A entrada em cena desta categoria, dos diretores, engenheiros e, até mesmo, dos trabalhadores ferroviários, como maquinistas, guarda-freios, chefes de estação, certamente abalou a estrutura social urbana pelotense. Não há como afirmar seguramente, por falta de fontes que atestem neste momento a hipótese, mas os detentores do conhecimento e do controle da via férrea e deste espaço urbano novo e peculiar poderiam ter se constituído em uma ameaça simbólica para hegemonia social de determinados grupos. Por isso, tantos atritos e tentativas de escancarar toda e qualquer falha proveniente daqueles.

Percebe-se, assim, também os conflitos que se originam neste espaço e as disputas entre quem fornece e usufrui do serviço. A cidade é lócus por excelência da tensão entre grupos sociais e é a partir desta que as sociabilidades, as práticas sociais e a construção de representaçôes ocorrem e adquirem sentido. Mais do 
que isto, são os valores disputados em conflitos sociais e intergrupais, na expressão de Michael Pollack (1992), que fazem com que esta relação passe do evento e da ocasião para uma constituição sensível do urbano.

\section{A CONSTRUÇÁO DE UMA VISUALIDADE E A EDUCAÇÁO DO OLHAR}

A Escola de Chicago, segundo Heitor Frúgoli Jr., aprofunda a noção de sociabilidade de Georg Simmel, considerando-a a partir de uma "concepçáo 'espacializada' do social e, reciprocamente, socializada do espaço” (2007:17). Nesta perspectiva, se a constituição material do espaço ferroviário possibilita novas sociabilidades e práticas sociais, estas também interferem na construção deste como representação. Quer-se focalizar, aqui, a representação imagética, ou seja, a passagem do simples "lugar" para imagem urbana, para paisagem.

Dessa forma, um estudo sobre o espaço e as vistas urbanas requer, primeiramente, um esclarecimento do que se compreende efetivamente por paisagem. $\mathrm{Na}$ medida em que se torna um "documento", o objeto de estudo da História nunca será a paisagem em si - na sua realidade concreta e pura - mas as representaçóes que se fez/fazem acerca dela. Sendo, assim, considera-se que a paisagem

Consiste na representação que dá a ver uma visualidade do espaço por meio de um artefato (imagem ou texto). Nesse sentido a paisagem é considerada uma composição sensível de acesso a cultura, uma forma de representação carregada de sentimentos, memórias e conhecimentos. Ela constrói laços de afinidade entre pessoas e ambiente; atribui sentido estético ao mundo que nos rodeia ao mesmo tempo em que age como verdadeira pedagogia do olhar. A paisagem é partícipe do que entendemos por cultura visual. (SAYÃO, 2011: 27)

A paisagem, nesta perspectiva, é representação do espaço que age neste mesmo espaço, intermediando a relação entre as pessoas e destas com a representação e o referente. A paisagem direciona o olhar, cria formas de visibilidade (e invisibilidade) e de visualidade; mostra o que se deve ver e de que forma ver. $\mathrm{Na}$ medida em que é partícipe de uma "cultura visual" isto significa que não é somente um elemento - o visual - de determinada cultura, mas que representa uma própria forma desta cultura se ver e se mostrar visualmente.

Além de todas estas características, Sayão lembra que o estudo da representação da paisagem nos remete à condição imagética da paisagem e que o trabalho de interpretação consiste no pleno exercício de leitura de imagem. A leitura, entretanto, não pode ser uma transposição das ideias lingüísticas, mas deve seguir a decodificação própria da imagem. Nesta perspectiva, como afirma Nelson Peixoto, "quando o olho dá lugar à vidência [enxergar, no visível, sinais invisíveis aos nossos olhos profanos], a imagem passa a ser tão legível quanto visível. A visibilidade da imagem torna-se uma legibilidade" (1998: 34).

Ao fim do século XIX acontece uma mudança na forma como as coisas passam a ser apreendidas e representadas; há um clima mental em que a instabilidade passa a ser o que marca e identifica a vida dos homens (HARDMAN, 2005:37). O "lugar próximo" adquiria um maior estranhamento e com a pulverização do tempo em "instantes inacessíveis" 
é desta forma fluida, volátil, vaporosa que se estava constituindo a paisagem típica da era urbano-industrial. Com efeito, o mundo das mercadorias está se convertendo, a partir de meados do século XIX, num gigantesco fantascópio. Alguns de seus contemporâneos, em meio a multidóes assombradas em face dos espetáculos mecânicos da modernidade, tentam representar as imagens desse novo poder de encantamento. (HARDMAN, 2005: 37-38)

A paisagem urbano-industrial a qual se refere o autor não diz respeito somente à materialidade dos espaços, mas ao próprio ambiente social e cultural que passa a marcar as relaçóes entre pessoas e lugares. As ferrovias são exemplo dessa forma vaporosa, fluida e volátil do mundo moderno, com a fumaça e a velocidade das locomotivas, o vai-e-vem dos passageiros, a passagem rápida de um local ao outro. Neste sentido, cria-se uma necessidade - e oportunidade - de buscar apreender toda a instabilidade e representar imageticamente o espetáculo moderno.

André Rouillé lembra, assim, que a fotografia foi a melhor resposta a esta necessidade, o que fez com que fosse projetada "no coração da modernidade, e que lhe valeu alcançar o papel de documento, isto é, o poder de equivaler legitimamente às coisas que ela representava" (2009: 31). A condição imagética das paisagens da Estação Férrea de Pelotas escolhida para análise neste trabalho é, então, a das fotografias.

A primeira fotografia elencada é de autoria do fotógrafo Augusto Amoretty, famoso por percorrer a zona sul do estado registrando a construçáo da estrada de ferro, fazendo parte da criação de uma "iconosfera" da ferrovia da regiáo. Possuía um estúdio próprio na cidade, a partir do qual se dava a provável circulação e recepção de suas imagens. Esta, em papel albuminado, data do ano de 1884 [Figura 1].

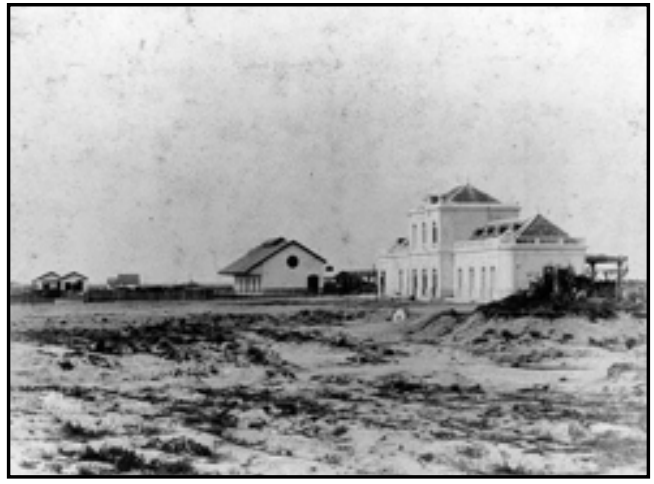

Figura 1 - Estação de Pelotas, Estrada de Ferro do Rio Grande a Bagé, Rio Grande do Sul, 1884. Fotógrafo: Augusto Amoretty. Acervo online do Itaú Cultural/Fundação Biblioteca Nacional.
Ao se observar a imagem, percebe-se a técnica de um fotógrafo profissional. Ampliando o plano de visibilidade, abarca grande parte da paisagem que circunda a estação, a qual deixa ao lado direito da composição. Mesmo que a centralidade da fotografia seja o vazio do terreno em frente ao prédio, este recebe maior luminosidade. A estação, no visível, demonstra toda sua imponência frente ao desbravado da paisagem, dominando o espaço e indicando uma determinada forma de olhar para a imagem. Em contrapartida, o direcionamento dado pelo fotógrafo deixa "invisível" o entorno, deslocando este espaço do restante do urbano. Isto, associado à vegetação, à presença da água e ao relevo - características mais voltadas à natureza - faz com que um observador que não possua o "modo de ver" apropriado, por um lado, não consiga associar a imagem à cidade e, por outro, tenha enfatizado o caráter grandioso e moderno da construção.

A segunda imagem, do ano de 1900, foi tomada pelo fotógrafo amador pelotense Henrique Patacão. Fixada também em papel albuminado, em preto 
\& branco, tem dimensóes de $11,8 \times 17,5 \mathrm{~cm}$, enquanto o cartão suporte mede $19,7 \times 25 \mathrm{~cm}$. Ressalta-se o péssimo estado de conservação desta fotografia (pertencente ao acervo da Bibliotheca Pública Pelotense), sendo esta uma reprodução da imagem do catálogo da coleção. Ainda que não se tenha acesso aos dados de circulação desta fotografia-artefato, presume-se que ela percorra o círculo social do fotógrafo, partindo de uma posição social de elite - mesmo que somente simbólica. Baseia-se esta hipótese no acesso deste homem às técnicas fotográficas e à sua revelação, sendo esta imagem da estação

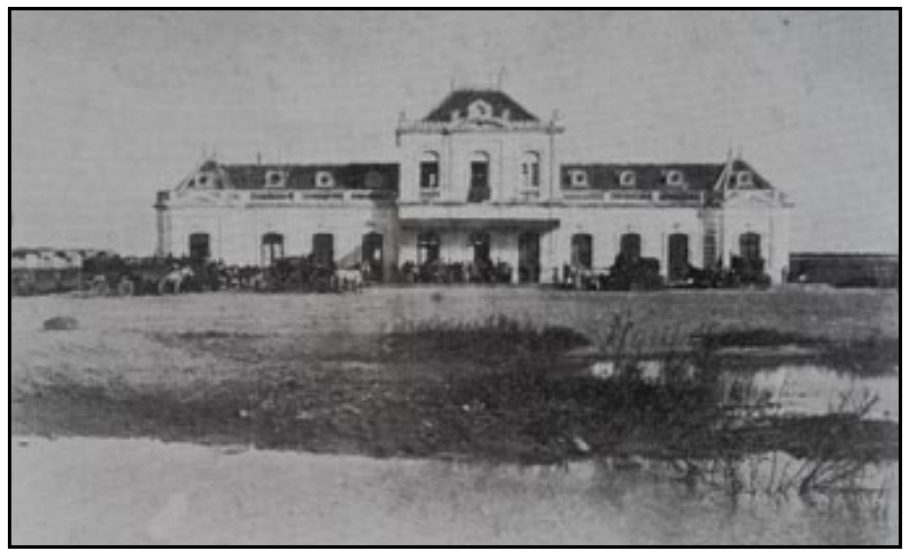

Figura 2 - Estação da Viação Férrea, 1900. Fotógrafo: Henrique Patacão. Acervo da Bibliotheca Pública Pelotense. somente uma dentre várias tomadas de vistas urbanas feitas por ele [Figura 2]

Observa-se nesta fotografia, em contraposição à anterior, que a Estação Férrea é o foco central, mas ainda ocupa um segundo plano. O primeiro plano, da mesma forma como na imagem de Amoretty, é tomado pela vegetação e pelo "banhado", denunciando as contradiçóes entre o terreno não domado e a suntuosidade de uma construçáo moderna de grande porte. Pode-se deduzir que Patacão teve acesso à fotografia de Amoretty, seguindo uma mesma visualidade. A visibilidade dada à movimentação de pessoas e carretas, entretanto, somada a um maior enquadramento do prédio, já permite um ar mais urbano. Com esta fotografia - ainda que não se possa afirmar que tenha sido a primeira - tem-se fixado a paisagem "ícone" da ferrovia em Pelotas: A Estação Férrea, vista de frente, lado voltado à cidade, local do encontro dos passageiros e dos que esperam.

De acordo com André Rouillé, para ver, precisamos de razão. O autor afirma que as visibilidades fotográficas, no século XIX, são inseparáveis dos fenômenos da modernidade, principalmente da urbanização. Contudo, acrescenta que "a fotografia só vê na cidade o cenário do poder: os monumentos que o fixam no passado, e as grandes obras urbanas que o projetam para o futuro" (ROUILLÉ, 2009: 45). Esta ideia é observável com as imagens da Estação Férrea de Pelotas. Nem tudo o que é urbano possui as características para se tornar "visível"; as fotografias representam a esperança do progresso e da modernidade que poderia advir com as locomotivas.

Nota-se, contudo, que a paisagem ferroviária representada imageticamente neste momento é deslocada do restante da cidade. Localizada mais próxima da periferia do que do centro urbano propriamente dito, a Estação ainda é um elemento "a parte", conflituoso, que necessita encontrar seu pertencimento. Da mesma forma como ocorria com as mudanças morfológicas e nas práticas sociais, a representação deste espaço vai sendo construída na experiência, ao mesmo tempo em - certamente - a modifica.

\section{Algumas CONSIDERAÇÓES E PROBLEMATIZAÇÓES...}

Partindo destas consideraçóes, percebe-se que a entrada da estrada de ferro e da Estação ferroviária no cenário urbano acarretam modificações, tanto na materialidade da cidade, como na forma como os citadinos se relacionam entre si e com o espaço, possibilitando a construção de representaçóes, imagens, sentidos e sensibilidades em relaçáo à cidade. Pensando-se que o campo das sensibilidades 
diz respeito não só à História, mas principalmente à memória, a análise destes processos históricos, mais do que auxiliar no entendimento da constituição da sociedade urbana pelotense, contribui para um olhar de compreensão da própria forma como esta cidade continua a se relacionar com o espaço ferroviário.

Neste sentido, é necessário observar que a memória não é compartimentada; ela faz referência sempre às questôes imateriais (sentidos, percepçōes, saberes, fazeres), os quais só ganham significação por estarem sustentados e localizados em algum espaço material específico, sendo inerentes às contradiçóes e sínteses resultantes desta relação. Ainda que, a priori, os limites possam ser percebidos, a lógica relacional entre o físico e as sensibilidades é muito mais complexa.

Atualmente a estação encontra-se totalmente abandonada, as águas furtadas não mais existem e se tornam visíveis para quem passa as telhas quebradas, as inscriçôes nas paredes, as portas e janelas fechadas com tijolos e cimento. Chama a atenção, assim, o descaso despendido a este espaço urbano, uma vez que materializa um processo importante da história urbana, social e econômica de Pelotas e do Estado.

Várias hipóteses podem ser levantadas - como a fixação por um discurso oficial de passado que remeta somente à opulência e à famílias tradicionais da cidade. Todas, no entanto, devem sempre levar a refletir sobre qual é a noçáo de memória e de patrimônio defendidas e por quem e para quem servem. Reforça-se, assim, a necessidade da disciplina da História se dedicar aos estudos da memória e da espacialidade urbanas. Ao analisar as diversas formas como são representados, pode-se fazer o jogo analítico das tensôes entre passado e presente dos espaços, compreendendo as formas como são praticados, apresentados e vistos ao longo do tempo.

\section{REFERÊNCIAS BIBLIOGRÁFICAS}

FRÚGOLI JR., Heitor. Sociabilidade Urbana. Rio de Janeiro: Jorge Zahar, 2007. HARDMAN, Francisco F. Trem-Fantasma: A Ferrovia Madeira-Mamoré e a Modernidade na Selva. 2a ed. São Paulo: Companhia das Letras, 2005.

IPHAE (Instituto do Patrimônio Histórico e Artístico do Estado). Patrimônio Ferroviário no Rio Grande do Sul: Inventário das Estaçóes 1874-1959. Porto Alegre: Pallotti, 2002.

LEFEBVRE, Henri. O Direito à Cidade. São Paulo: Centauro, 2001.

MAGALHÁES, Mário Osório. Opulência e Cultura na Província de São Pedro do Rio Grande do Sul: Um Estudo Sobre a História de Pelotas (1860-1890). Pelotas: EdUFPel/Livraria Mundial, 1993.

PEIXOTO, Nelson Brissac. Paisagens Urbanas. 2a ed. São Paulo: Senac/Marca D’Água, 1996.

POLLAK, Michel. "Memória e identidade social. Estudos históricos". Rio de Janeiro, vol. 5, n. 10, 1992, p.200-215.

ROUILLÉ, André. A Fotografia: Entre Documento e Arte Contemporânea. São Paulo: Ed. Senac, 2009.

SAYÃO, Thiago J. "(Re)Tratos Insulares: A Ilha de Santa Catarina vista através das representaçóes das paisagens (1890-1940)". Porto Alegre, 2011. Dissertação (Mestrado em História). Universidade Federal do Rio Grande do Sul. 